ISSN 0103-8478

\title{
Mudanças químicas e viscoamilográficas em farinhas de diferentes genótipos de arroz submetidas à extrusão
}

\author{
Changes in chemical and viscoamylographic in flour from different \\ rice genotypes subjected to extrusion
}

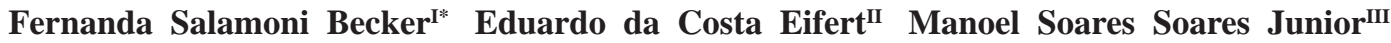 \\ July Ana Souza Tavares ${ }^{I}$ Ana Vânia Carvalho ${ }^{I V}$
}

RESUMO

A grande quantidade de grãos quebrados resultante do beneficiamento do arroz e seu baixo valor comercial tem levado as indústrias a buscarem alternativas para agregar valor a esse subproduto. O objetivo deste estudo foi avaliar as mudanças químicas e as propriedades viscoamilográficas em farinhas de arroz, obtidas a partir de grãos quebrados dos genótipos Irga 417, BRS Primavera e CNA 8502, submetidas ao processo de extrusão. Utilizou-se delineamento experimental inteiramente ao acaso, tipo fatorial 3x2, com quatro repetições originais e análise de variância para avaliar os dados obtidos. As farinhas dos diferentes materiais genéticos diferiram quanto ao valor nutricional e tecnológico. A farinha nativa da linhagem CNA 8502 apresentou maior teor de

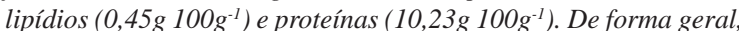
as farinhas da Irga 417 apresentaram maiores teores de cinzas

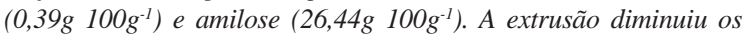
teores de umidade e lipídios, elevou o teor de amilose, não afetou os teores de cinzas e proteínas e reduziu os valores de pico de viscosidade, viscosidade final, quebra de viscosidade e tendência à retrogradação, porém a magnitude da resposta dependeu das características inerentes a cada genótipo. As farinhas extrusadas apresentam potencial para aplicação em produtos instantâneos ou como ingrediente para produtos alimentícios nos quais são exigidas menores viscosidades, quando servidos a quente ou a frio, que suportem a agitação e retrogradem menos quando sejam resfriados.

Palavras-chave: grãos quebrados, subproduto, Oryza sativa $L$.

\section{ABSTRACT}

The large amount of broken grains resulted from rice processing and its low commercial value have led industries to find alternatives to add value to this by product. The objective of this study was to evaluate the chemical and viscolamylographic properties changes in rice flour made from broken grains of genotypes IRGA 417, BRS Primavera and CNA 8502, subject to the extrusion process. It was used a randomized experimental design, type $3 \times 2$ factorial with four replications, and variance analysis to evaluate the data obtained for this. The flours of different genotypes differed on the nutritional value and technology. Native flour of CNA 8502 had a higher lipid content $\left(0.45{\left.\mathrm{~g} 100 \mathrm{~g}^{-1}\right) \text { and }}\right.$

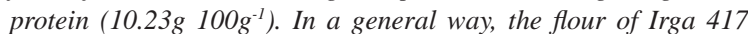

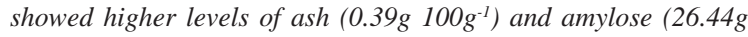
$\left.100 \mathrm{~g}^{-1}\right)$. Extrusion decreased the levels of moisture and lipids, increased the amylose content, didn't affect the ash and protein contents and reduced the viscosity peak, final viscosity, breakdown viscosity and retrogradation tendency, but the magnitude of the response depended of the defining features inherent genotypes. The extruded flours have potential for use in instant products or as an ingredient for food products in which lower viscosities are required when served hot or cold, supporting the agitation and retrograde least when they are cooled.

Key words: broken grains, by product, Oryza sativa $L$.

\section{INTRODUÇÃO}

Trigo, milho e arroz são os cereais de maior importância mundial, constituindo a base da alimentação humana e contribuindo com cerca da metade da ingestão energética e proteica dos indivíduos (FAO, 2007). Os dois primeiros cereais são ingredientes alimentares, normalmente transformados em farinha ou amido, ao contrário do arroz, consumido no Brasil principalmente na forma de grãos inteiros (CAVALHEIRO et al., 2007).

IPós-graduação em Ciência e Tecnologia de Alimentos, Universidade Federal de Goiás (UFG), Campus Samambaia, CP 131, 74690-900, Goiânia, GO, Brasil. E-mail: fsb.fernanda@hotmail.com.*Autor para correspondência.

"Empresa Brasileira de Pesquisa Agropecuária, Embrapa Arroz e Feijão, Santo Antônio de Goiás, GO, Brasil.

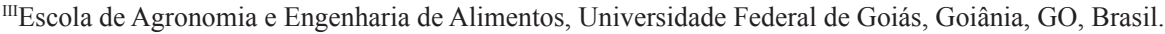

${ }^{\mathrm{IV}}$ Empresa Brasileira de Pesquisa Agropecuária, Embrapa Amazônia Oriental, Belém, PA, Brasil. 
O Brasil destaca-se como o maior produtor de arroz da América Latina e o nono produtor mundial (FAO, 2007). O país obteve produção de 13.461,4 mil toneladas de arroz em casca na safra 2010/2011 (CONAB, 2011). Os grãos quebrados e quirera, subprodutos do beneficiamento do arroz, representam cerca de $14 \%$ do total do arroz beneficiado, ou seja, sua produção no país na safra 2010/2011 foi ao redor de 1.884,6 mil toneladas. O valor comercial desse subproduto é de cerca de $1 / 5$ do preço dos grãos inteiros, sendo utilizado basicamente na indústria cervejeira, em vinícolas e na alimentação animal (LIMBERGER et al., 2008). Considerando a composição química dos grãos quebrados, ricos em amido (75-80\%), a produção de farinha de arroz é uma alternativa para agregar valor a esse subproduto (SHENG, 1995). Para a indústria de alimentos, a farinha de arroz é um ingrediente atrativo pelos seus atributos como textura suave, sabor e aroma brandos, cor branca atrativa, hipoalergenicidade, e baixos níveis de sódio (KADAN et al., 2003).

A extrusão altera as propriedades tecnológicas de farinhas, pela compressão desta contra uma matriz, em condições de aquecimento e pressão que levam à gelatinização do amido (HAGENIMANA et al., 2006). Esse processo tem proporcionado numerosas aplicações na indústria alimentícia, com a elaboração de produtos a base de cereais, leguminosas e de féculas de raízes e tubérculos; tais como cereais matinais, petiscos, snacks, macarrões, alimentos a base de cereais enriquecidos com proteína, bebidas em pó, proteína de soja texturizada, farinhas e amidos pré-gelatinizados, utilizados na formulação de sopas de preparo rápido, molhos, produtos de confeitaria, entre outros (BOONYASIRIKOOL \& CHARUNUCH, 2000; CHEYNE et al., 2005; CHUANG \& YEH, 2004).

As cultivares de arroz 'IRGA 417' e 'BRS Primavera' são os principais materiais genéticos utilizados na produção de arroz irrigado e de terras altas, respectivamente. Enquanto essas cultivares têm tempo médio de cozimento de $10 \mathrm{~min}$, resultando em grãos macios e levemente soltos, a linhagem CNA 8502 apresenta maior tempo de cozimento (26min), com grãos macios e levemente pegajosos, o que exemplifica as diferenças químicas e tecnológicas entre diferentes materiais genéticos de arroz. O teor de amilose é importante característica das cultivares de arroz, pois, além da qualidade de cozimento, determina características importantes em relação às propriedades viscoamilográficas. O teor de amilose da cultivar 'CNA 8502', obtido por SANTOS et al. (2002), foi de $30 \mathrm{~g} 100 \mathrm{~g} 100^{-1}$. O teor de lipídios também é importante, pois os ácidos graxos de mono e diglicerídios formam complexo com a amilose, alterando suas características em relação às propriedades de hidratação, expansão, textura e viscosidade (SOARES JÚNIOR et al., 1999)

$\mathrm{O}$ arroz caracteriza-se por alta porcentagem de amido (74,12 a 87,58\%), logo as propriedades viscoamilográficas de farinhas nativas e prégelatinizadas de arroz assumem grande importância quando da aplicação desses materiais na indústria em alimentos, que necessitam ou não de espessamento ou retenção de água sem o emprego de calor (WALTER et al., 2008; KADAN et al., 2003; HAGENIMANA et al., 2006). Assim, este estudo teve como objetivo analisar as mudanças ocorridas pelo uso da extrusão, nas características químicas e nas propriedades viscoamilográficas de farinhas obtidas a partir de grãos quebrados de diferentes genótipos de arroz, visando a ampliação da utilização dessas farinhas pela indústria de alimentos.

\section{MATERIAL E MÉTODOS}

Utilizaram-se grãos quebrados de Oryza sativa L., safra 2008, das cultivares 'IRGA 417' e 'BRS Primavera' e da linhagem CNA 8502, o primeiro oriundo de Pelotas - RS e os demais provenientes do programa de melhoramento de arroz da Embrapa Arroz e Feijão, Santo Antônio de Goiás, GO. Foram elaboradas farinhas dos três materiais genéticos, nativas e extrusadas, em delineamento inteiramente casualizado, tipo fatorial $3 \times 2$, com quatro repetições originais. Para tanto, os grãos quebrados de arroz foram triturados em moinho de facas (Perten Instruments, Laboratory Mill 3100, Estocolmo, Suécia) para obtenção das farinhas nativas, que foram homogeneizadas, acondicionadas em embalagens plásticas (polietileno de baixa densidade) e armazenadas sob temperatura ambiente até a realização das análises.

Cerca de $50 \%$ da farinha nativa obtida de cada genótipo foi destinada ao processo de extrusão; condicionadas a $17 \%$ de umidade pela adição água destilada. Em seguida, as farinhas foram armazenadas em embalagens de polietileno de baixa densidade, a temperaturas de $7 \pm 1^{\circ} \mathrm{C}$, durante $24 \mathrm{~h}$, para homogeneização da umidade. A extrusão foi realizada em extrusora mono-rosca (INBRAMAQ, RXPQ Labor 24, Ribeirão Preto, Brasil), com capacidade de produção semi-industrial, e os parâmetros fixos da extrusão foram: camisa helicoidal, rosca curta com taxa de compressão de 3:1, matriz circular de $3,85 \mathrm{~mm}$; temperatura na $1^{\underline{a}}$ zona de aquecimento de 
$40^{\circ} \mathrm{C}$, na $2^{\text {a }}$ de $60^{\circ} \mathrm{C}$ e na $3^{\text {a }}$ de $80^{\circ} \mathrm{C}$; velocidade de alimentação de $218 \mathrm{~g} \mathrm{~min}^{-1}$ e velocidade do parafuso de 180rpm. As farinhas pré-gelatinizadas foram obtidas pela trituração dos extrusados em moinho de facas (Perten, Laboratory Mill 3100), acondicionadas em embalagem de polietileno de baixa densidade e armazenadas à temperatura ambiente, até a realização das análises químicas e tecnológicas. As farinhas nativas e extrusadas foram peneiradas em malha de aço inox de 60 mesh, utilizando-se, para a realização das análises, as porções passantes.

Os teores de umidade, proteína bruta (fator de conversão de 5,95), lipídios e cinzas foram determinados segundo metodologias da AOAC INTERNATIONAL (1997); a concentração de amilose foi determinada por meio de técnica colorimétrica, desenvolvida por MARTINÉZ \& CUEVAS (1989) e adaptada pelo Laboratório de Grãos e Subprodutos da Embrapa Arroz e Feijão, utilizando-se como indicador a solução de iodeto de potássio. O complexo formado foi medido em espectrofotômetro (620nm) e a curva de calibração foi obtida utilizando-se diversas diluições de amilose de batata, código A-0512, Sigma ${ }^{\circledR}$. Como testemunhas, utilizaram-se as variedades de arroz Colômbia 1, Bluebonnet 50 e IR 8, pois estas possuem teores de amilose baixo, intermediário e alto, respectivamente.

As curvas viscoamilográficas foram obtidas segundo método oficial para arroz no ${ }^{-61-}$ 02 da AACC (2000), em equipamento Rapid Visco Analyser série 4 (Newport. Scientific Warriewood, Austrália). Utilizou-se a programação Rapid Visco do software Thermocline for Windows versão 2.2. A suspensão formada pelo amido e a água foi inicialmente cisalhada a 960rpm durante $10 \mathrm{~s}$, mantida a $50^{\circ} \mathrm{C}$ por $3 \mathrm{~min}$ e $45 \mathrm{~s}$, para investigar a viscosidade do amido à baixa temperatura. Posteriormente, a mistura foi aquecida a $95^{\circ} \mathrm{C}$ sob velocidade constante de $14^{\circ} \mathrm{C} \mathrm{min}^{-1}$, mantida nessa temperatura por $3 \mathrm{~min}$ e $30 \mathrm{~s}$, resfriada a $50^{\circ} \mathrm{C}$ durante $4 \mathrm{~min}$ e $10 \mathrm{~s}$ sob a mesma velocidade, e mantida a $50^{\circ} \mathrm{C}$ por mais $1 \mathrm{~min}$ e $25 \mathrm{~s}$, totalizando $12 \mathrm{~min}$ e $30 \mathrm{~s}$ de análise. Avaliaramse as características de pico de viscosidade (PV), viscosidade final (VF), quebra de viscosidade (QV) ou breakdown e tendência à retrogradação (TR) ou setback, expressos na unidade do aparelho, Rapid Visco Units (RVU).

Todas as análises foram realizadas, para cada repetição original, em quadruplicata, e os dados obtidos foram submetidos à análise de variância (Anova), sendo as médias comparadas pelo teste Tukey a $5 \%$ de probabilidade de erro, utilizando-se o aplicativo SAS for Windows, versão 8.1 (SAS, 2003).

\section{RESULTADOS E DISCUSSÃO}

Os valores médios de alguns componentes químicos das farinhas de arroz nativas e extrusadas dos genótipos IRGA 417, BRS Primavera e CNA 8502 estão expressos na tabela 1 . As farinhas de arroz diferiram entre si quanto ao conteúdo de umidade, ocorrendo interação significativa $(\mathrm{P} \leq 0,05)$ no teor de umidade para efeito de genótipo e tratamento industrial. O teor de umidade das farinhas dos três genótipos reduziu quando estas foram extrusadas, tendo-se maior redução para IRGA 417 (23,47\%), seguida pelos genótipos BRS Primavera (10,48\%) e CNA 8502 (9,87\%). Essa redução é resultado da passagem repentina da água do estado líquido para vapor, devido à queda de pressão na saída da matriz, o que causa expansão do produto (BARBOSA et al., 2006). Para IRGA 417, houve redução mais que dobrada de umidade em relação aos outros dois genótipos, provavelmente devido ao maior teor de umidade da farinha de arroz crua dessa cultivar (Tabela 1), que representou quantidade maior de água livre no produto.

O processo de extrusão não exerceu influência sobre o teor de cinzas das farinhas de arroz (Tabela 1), entretanto, os genótipos diferiram quanto a essa medida. $O$ conteúdo mineral fixo foi maior na farinha da Irga $417(\mathrm{P} \leq 0,05)$. As farinhas da CNA 8502 e da BRS Primavera não diferiram entre si $(\mathrm{P}>0,05)$ em relação ao teor de cinzas, apesar de possuírem sistemas de produção diferente (irrigado e de terras altas, respectivamente). O conteúdo mineral do arroz é influenciado pela genética, mas também pode variar de acordo com o clima, tipo de solo e tratos culturais.

Verificou-se interação significativa $(\mathrm{P} \leq 0,05)$ dos efeitos de genótipo e tratamento industrial quanto aos teores de lipídios. Houve redução dos teores de lipídios nas farinhas extrusadas em relação às farinhas nativas nos três genótipos avaliados (Tabela 1), devido à formação de interações moleculares envolvendo esses constituintes (BRYANT et al., 2001). A extração de lipídios a partir de produtos extrusados fica comprometida, já que, durante a extrusão, as moléculas de lipídios podem se ligar a outros componentes do alimento, como proteínas e carboidratos, alterando sua estrutura química e dificultando a sua análise (CAMIRE et al., 1990). Fato este observado por BARBOSA et al. (2006), que determinaram teores de lipídios na farinha nativa de arroz de $0,73 \%$ e na farinha extrusada de $0,28 \%$, valores maiores que os obtidos no presente trabalho. 
Tabela 1 - Composição química e propriedades viscoamilográficas de farinhas de arroz nativas e extrusadas dos genótipos IRGA 417, BRS Primavera e CNA 8502 (base seca) ${ }^{1}$.

\begin{tabular}{|c|c|c|c|c|c|}
\hline Componente/Propriedade & Tratamento & IRGA 417 & BRS Primavera & CNA 8502 & Média Total \\
\hline \multirow{2}{*}{ Umidade } & Nativa & $12,27 \pm 0,03^{\mathrm{Aa}}$ & $10,21 \pm 0,08^{\mathrm{Ca}}$ & $10,54 \pm 0,07^{\mathrm{Ba}}$ & - \\
\hline & Extrusada & $9,39 \pm 0,05^{\mathrm{Bb}}$ & $9,14 \pm 0,05^{\mathrm{Cb}}$ & $9,50 \pm 0,02^{\mathrm{Ab}}$ & - \\
\hline \multirow{3}{*}{ Cinzas } & Nativa & $0,40 \pm 0,01$ & $0,39 \pm 0,01$ & $0,32 \pm 0,01$ & - \\
\hline & Extrusada & $0,39 \pm 0,01$ & $0,31 \pm 0,05$ & $0,32 \pm 0,01$ & - \\
\hline & MG & $0,39^{\mathrm{A}}$ & $0,30^{\mathrm{B}}$ & $0,32^{\mathrm{B}}$ & - \\
\hline \multirow{2}{*}{ Lipídios } & Nativa & $0,34 \pm 0,01^{\mathrm{Ba}}$ & $0,37 \pm 0,01^{\mathrm{Ba}}$ & $0,45 \pm 0,03^{\mathrm{Aa}}$ & - \\
\hline & Extrusada & $0,24 \pm 0,01^{\mathrm{Ab}}$ & $0,25 \pm 0,02^{\mathrm{Ab}}$ & $0,20 \pm 0,01^{\mathrm{Bb}}$ & - \\
\hline \multirow{3}{*}{ Proteína } & Nativa & $8,52 \pm 0,10^{\mathrm{Ca}}$ & $8,90 \pm 0,16^{\mathrm{Bb}}$ & $10,23 \pm 0,08^{\mathrm{Aa}}$ & - \\
\hline & Extrusada & $8,64 \pm 0,08^{\mathrm{Ca}}$ & $10,33 \pm 0,10^{\mathrm{Aa}}$ & $10,12 \pm 0,08^{\mathrm{Ba}}$ & - \\
\hline & Nativa & $25,63 \pm 0,56$ & $24,40 \pm 0,73$ & $23,00 \pm 0,45$ & $24,34^{\mathrm{b}}$ \\
\hline \multirow[t]{2}{*}{ Amilose } & Extrusada & $27,24 \pm 0,81$ & $25,98 \pm 0,22$ & $23,41 \pm 0,30$ & $25,55^{\mathrm{a}}$ \\
\hline & MG & $26,44^{\mathrm{A}}$ & $25,19^{\mathrm{B}}$ & $23,21^{\mathrm{C}}$ & - \\
\hline \multirow{2}{*}{ Pico de Viscosidade } & Nativa & $241,53 \pm 2,30^{\mathrm{Aa}}$ & $192,94 \pm 7,17^{\mathrm{Ca}}$ & $204,97 \pm 1,12^{\mathrm{Ba}}$ & \\
\hline & Extrusada & $42,94 \pm 1,43^{\mathrm{Ab}}$ & $41,16 \pm 0,52^{\mathrm{Ab}}$ & $33,47 \pm 1,18^{\mathrm{Bb}}$ & \\
\hline \multirow{2}{*}{ Viscosidade Final } & Nativa & $472,86 \pm 2,00^{\mathrm{Aa}}$ & $319,42 \pm 6,16^{\mathrm{Ba}}$ & $312,94 \pm 1,73^{\mathrm{Ba}}$ & \\
\hline & Extrusada & $24,78 \pm 0,63^{\mathrm{Ab}}$ & $19,06 \pm 0,49^{\mathrm{Bb}}$ & $17,20 \pm 0,71^{\mathrm{Bb}}$ & \\
\hline \multirow{2}{*}{ Quebra de Viscosidade } & Nativa & $16,72 \pm 1,52^{\mathrm{Bb}}$ & $63,17 \pm 3,19^{\mathrm{Aa}}$ & $58,92 \pm 0,09^{\mathrm{Aa}}$ & \\
\hline & Extrusada & $25,33 \pm 0,93^{\mathrm{Ba}}$ & $29,89 \pm 0,41^{\mathrm{Ab}}$ & $22,08 \pm 0,80^{\mathrm{Cb}}$ & \\
\hline \multirow{2}{*}{ Tendência retrogradação } & Nativa & $231,3 \pm 1,06^{\mathrm{Aa}}$ & $126,47 \pm 1,40^{\mathrm{Ba}}$ & $107,97 \pm 0,92^{\mathrm{Ca}}$ & \\
\hline & Extrusada & $-18,1 \pm 0,80^{\mathrm{Ab}}$ & $-22,1 \pm 0,05^{\mathrm{Bb}}$ & $-16,28 \pm 1,47^{\mathrm{Ab}}$ & \\
\hline
\end{tabular}

${ }^{1}$ Valores correspondem à média \pm desvio-padrão; Letras diferentes, maiúsculas (mesma linha) e minúsculas (mesma coluna), diferem significativamente pelo teste Tukey $(\mathrm{P} \leq 0,05)$.

O processo de extrusão não afetou o teor de proteínas das farinhas extrusadas com relação às nativas da cultivar 'IRGA 417' e da linhagem CNA $8502(\mathrm{P}>0,05)$. Houve interação significativa $(\mathrm{P} \leq 0,05)$ para o conteúdo proteico entre os genótipos e tratamento industrial. As farinhas nativas diferiram entre si $(\mathrm{P} \leq 0,05)$ quanto ao conteúdo proteico (Tabela 1), assim como as farinhas extrusadas dos três genótipos avaliados, devido às características biomoleculares intrínsecas do endosperma do fruto de cada cultivar de arroz. Na cultivar 'BRS Primavera', ocorreu um aumento do teor de proteína na farinha extrusada $(\mathrm{P} \leq 0,05)$, provavelmente, devido à incompleta homogeneização das amostras analisadas.

Quanto ao conteúdo de amilose, todos os genótipos foram classificados como de amilose intermediária (22 a 27\%). O genótipo e o tratamento industrial isoladamente exerceram efeito significativo no conteúdo de amilose em um intervalo de confiança de $95 \%$, sem ocorrer o efeito de interação. Avaliando- se o efeito do genótipo, observa-se que os valores médios de amilose diferiram entre si $(\mathrm{P} \leq 0,05)$ entre os materiais genéticos estudados, sendo superior na IRGA 417, seguida pela BRS Primavera e CNA 8502 (Tabela 1). As diferenças nos teores de amilose entre as cultivares avaliadas neste estudo confirmam as variadas proporções, relatadas na literatura científica, entre amilose e amilopectina, que existem entre os amidos de cada cultivar de arroz (WALTER; MARCHEZAN, DE ÁVILA, 2008). O arroz pode ser classificado quanto ao teor de amilose em: ceroso (1$2 \%$ de amilose), não ceroso ( $>2 \%$ de amilose), muito baixa (2-9\% de amilose), intermédio (20-25\% de amilose) e alto (25-33\% de amilose).

Com a extrusão, houve aumento do teor de amilose. O amido é composto por unidades de D-glicose, organizadas em dois homopolissacarídeos: a amilose e a amilopectina. A amilose praticamente não apresenta ramificações, sendo que as unidades de glicose são conectadas por ligações glicosídicas 
do tipo $\alpha(1,4)$ e a porcentagem de ramificações $\alpha(1,6)$ é menor do que $1 \%$ (BALL et al., 1998). A amilopectina é altamente ramificada e possui cadeias de resíduos de glicose ligados entre si por ligações glicosídicas do tipo $\alpha(1,4)$, com aproximadamente $5 \%$ de ramificações $\alpha(1,6)$ (MYERS et al., 2000). Durante o processo de extrusão, pode ter ocorrido o rompimento de algumas ramificações da cadeia da amilopectina, gerando cadeias lineares semelhantes a da amilose, que seriam detectadas pelo método utilizado na determinação de amilose. O aumento da amilose após a extrusão provavelmente influenciou nas propriedades de massa das farinhas de arroz.

Houve efeito de interação significativa $(\mathrm{P} \leq 0,05)$ entre genótipo e tratamento industrial para todas as propriedades viscoamilográficas analisadas. Os valores de pico de viscosidade (PV), viscosidade final (VF), quebra de viscosidade (QV) e tendência à retrogradação (TR) das farinhas nativas e extrusadas dos genótipos IRGA 417, BRS Primavera e CNA 8502 estão apresentados na tabela 1. Correlações significativas ocorreram entre os componentes químicos e as propriedades viscoamilográficas avaliadas. As correlações entre pico de viscosidade com umidade $(\mathrm{r}=0,87)$ e com lipídio $(\mathrm{r}=0,88)$, viscosidade final com umidade $(\mathrm{r}=0,92)$ e com lipídio $(\mathrm{r}=0,81)$, quebra de viscosidade com lipídios $(\mathrm{r}=0,71)$, tendência à retrogradação com umidade $(\mathrm{r}=0,95)$ e com lipídio $(\mathrm{r}=0,72)$ foram positivas e significativas a $1 \%$ de probabilidade de erro. Enquanto as correlações entre quebra de viscosidade com teor de amilose $(\mathrm{r}=-0,48)$ e com cinzas $(\mathrm{r}=-0,56)$ e entre tendência à retrogradação com proteínas $(\mathrm{r}=$ 0,48 ) foram negativas e apresentaram nível de $5 \%$ de significância.

As farinhas de arroz nativas apresentaram picos de viscosidade diferentes entre si $(\mathrm{P} \leq 0,05)$ e superiores aos das farinhas extrusadas (Figura 1), principalmente devido à gelatinização do amido durante o processo de extrusão. Nas farinhas extrusadas, os valores de PV não diferiram $(\mathrm{P}>0,05)$ entre os genótipos IRGA 417 e BRS Primavera, mas sim da CNA $8502(\mathrm{P} \leq 0,05)$, que apresentou o menor valor, devido ao seu maior teor de umidade e menores teores de lipídio e amilose (Tabela 1). A variação de PV indica diferentes graus de gelatinização e destruição da estrutura cristalina dos grânulos de amido nas farinhas extrusadas. $\mathrm{O}$ aumento de viscosidade com a elevação da temperatura no ciclo de aquecimento ocorre pela perda parcial das pontes de hidrogênio, que unem as frações presentes no amido, originando sítios hidrofílicos que se ligam às moléculas de água, aumentando a solubilidade do amido e a viscosidade a quente (ASCHIERI \& CARVALHO, 2006). ELSAIED et al. (1979) constataram que o conteúdo de proteína foi negativamente correlacionado com o PV. A proteína pode atuar como uma barreira física para o intumescimento do amido, uma vez que os grânulos de amido são encaixados na matriz de proteína. Isso pode explicar os maiores valores de PV nas farinhas nativas e extrusadas do genótipo IRGA 417, já que ele apresentou menores teores de proteínas que os demais genótipos avaliados.

Ocorreu redução na viscosidade final (VF) das farinhas nativas quando comparadas com as extrusadas. Tanto nas farinhas nativas quanto nas extrusadas, a IRGA 417 apresentou maiores valores de $\operatorname{VF}(\mathrm{P} \leq 0,05)$, enquanto que as demais farinhas não diferiram entre si $(\mathrm{P}>0,05)$. Baixos valores de VF são obtidos em tratamentos severos, onde ocorre degradação dos grânulos de amido e possíveis rompimentos de suas estruturas moleculares, que causam a perda da capacidade de retrogradação delas e diminui a viscosidade no resfriamento (SEBIO, 1996), o que ocorreu durante a extrusão no presente trabalho. Quanto maior o teor de umidade na farinha de arroz nativa (Tabela 1), mais brando foi o processo de extrusão, uma vez que esse componente da matériaprima atua como lubrificante durante o processo de extrusão, resultando em uma maior viscosidade final do Irga-217. Durante o resfriamento, as pastas de amido nativo normalmente tendem à retrogradação, implicando o aumento da VF (ASCHERI et al., 2006).

As farinhas nativas da BRS Primavera e da CNA 8502 apresentaram os maiores valores de breakdown, não diferindo entre si $(\mathrm{P}>0,05)$, mas da Irga $417(\mathrm{P} \leq 0,05)$, porque esta possuía os maiores teores de cinzas e amilose, e menor teor de lipídios. Já nas farinhas extrusadas, os valores de quebra de viscosidade diferiram entre todos os genótipos $(\mathrm{P} \leq 0,05)$, sendo maior na BRS Primavera e menor na CNA 5802. Houve uma redução significativa $(\mathrm{P} \leq 0,05)$ dos valores dessa propriedade nas farinhas da BRS Primavera e CNA 8502 após a extrusão, enquanto que, para a da Irga 417, houve um aumento $(\mathrm{P} \leq 0,05)$. A redução dos valores de breakdown nas farinhas extrusadas era esperada, uma vez que os picos de viscosidade destas foram menores que os das nativas (Figura 1), além da degradação sofrida pelo amido durante o processo de extrusão.

Todas as farinhas nativas diferiram entre si $(\mathrm{P} \leq 0,05)$ quanto ao valor de setback, sendo as menores tendências à retrogradação verificadas na CNA 8502, seguidos pela BRS Primavera e Irga 417. Já nas extrusadas, as da CNA 8502 e da Irga 417 não diferiram entre si $(\mathrm{P}>0,05)$, mas diferiram 


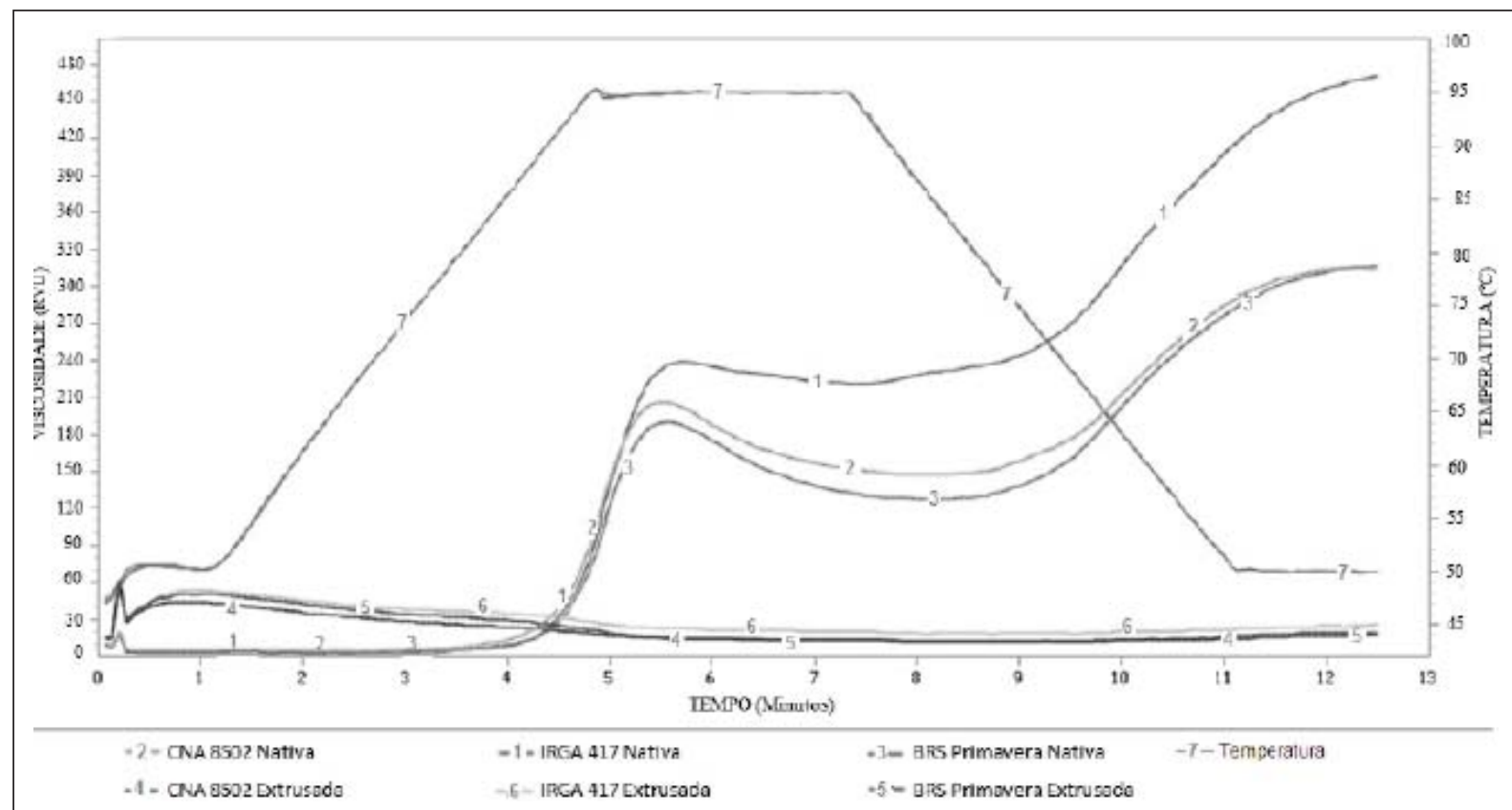

Figura 1 - Perfis das curvas de viscosidade das farinhas nativas e extrusadas dos genótipos IRGA 417, BRS Primavera e CNA 8502.

dos valores do BRS Primavera $(\mathrm{P} \leq 0,05)$, que obteve a maior média. O menor teor de proteína da farinha de arroz extrusada da BRS Primavera pode ter ocasionado a maior tendência à retrogradação em relação à IRGA 417 e CNA 5802. O Setback reflete o grau de retrogração da pasta de amido; quanto menor o setback, menor a retrogradação e, consequentemente, a sinerese (LIMBERGER et al., 2008). Em função dos baixos valores de tendência de retrogradação obtidos, as farinhas extrusadas da CNA 5802 e da Irga 417 podem ser mais adequadas para obtenção de produtos nos quais se pretenda evitar a sinerese, como alimentos congelados. Entretanto, as farinhas extrusadas de arroz das três cultivares apresentam potencial para aplicação em produtos instantâneos ou como ingrediente alimentício para produtos em que sejam exigidas menores viscosidades, quando servidos a quente ou a frio, que suportem a agitação e não retrogradem quando sejam resfriados, como bebidas lácteas, molhos para saladas e alimentos infantis.

\section{CONCLUSÃO}

Em geral, as farinhas nativas da Irga 417 e da CNA 8502 apresentaram-se com mais umidade, cinzas e amilose e menos lipídios e proteínas que a BRS Primavera. A extrusão promoveu alterações nas propriedades viscoamilográficas das farinhas, porém a magnitude da resposta dependeu da composição química da matéria-prima, dependente do genótipo de cada arroz avaliado. A partir do processo de extrusão, foi possível a obtenção de farinhas de arroz extrusadas com valores reduzidos de pico de viscosidade, quebra de viscosidade, viscosidade final e tendência à retrogradação. As farinhas extrusadas das cultivares 'Irga 417' e 'CNA 5802' apresentaram maiores pico de viscosidade e viscosidade final, e menores quebra de viscosidade e tendência à retrogradação.

\section{AGRADECIMENTOS}

À Fundação de Amparo à Pesquisa do Estado de Goiás (FAPEG) e à Coordenação de Aperfeiçoamento de Pessoal de Nível Superior (CAPES), pelo apoio financeiro, e à Capes pela bolsa de Mestrado.

\section{REFERÊNCIAS}

AACC (AMERICAN ASSOCIATION OF CEREAL CHEMISTS). Approved methods. 10.ed. Saint Paul, 2000. V.1 e 2.

AOAC (ASSOCIATION OF OFFICIAL ANALYTICAL CHEMISTRY). Official methods of analysis of AOAC International: food composition, additives, natural contaminants. 16.ed. Gaithersburg, 1997. V.2.

ASCHERI, D.P.R. et al. Obtenção de farinhas mistas prégelatinizadas a partir de arroz e bagaço de jabuticada: efeito das variáveis de extrusão nas propriedades de pasta. Boletim do CEPPA, v.24, n.1, p.115-144, 2006.

ASCHERI, J.L.R.; CARVALHO, C.W.P. Características de fubá extrusado. Rio de Janeiro: Embrapa, 2006. 3p. (Comunicado Técnico, 98). 
BALL, S.G. et al. Progress in understanding the biosynthesis of amylose. Trends in Plant Science, v.3, p.462-467, 1998. Disponível em: $<$ http://www.sciencedirect.com/science?_ob=ArticleListURL\&_ method=list\&_ArticleListID $=1706423676 \&$ \& sort $=$ r\& $\mathrm{st}=13 \&$ view $=\mathrm{c} \&$ a $\mathrm{acct}=\mathrm{C} 000050221 \&$ _version $=1 \&$ _urlVersion $=0$ \&_ userid=10\&md5=21 fb832ee7126ade56a $77 \mathrm{c} 18 \mathrm{~d} 7 \mathrm{dac} 176 \&$ searchtype =a $>$. Acesso em: 04 abr. 2011. doi: 10.1016/S1360-1385(98)01342-9. doi: 10.1016/S1360-1385(98)01342-9.

BARBOSA, L.N. et al. Elaboração de embutido tipo mortadela com farinha de arroz. Vetor, v.16, n.1 e 2, p.11-20, 2006.

BOONYASIRIKOOL, P.; CHARUNUCH, C. Development of corngrit-broken rice based food by extrusion cooking. National Science, v.34, p.279-288, 2000.

BRYANT, R.J. et al. Functional and digestive characteristics of extruded rice flour. Cereal Chemistry, v.78, n.2, p.131-137, 2001. Disponível em: <http://cerealchemistry.aaccnet.org/doi/ pdf/10.1094/CCHEM.2001.78.2.131>. Acesso em: 15 jan. 2011. doi: 10.1094/CCHEM.2001.78.2.131.

CAMIRE, M.E. et al. Chemical and nutritional changes in foods during extrusion. Critical Reviews in Food Science and Nutrition, v.29, n.1, p.35-57, 1990. Disponível em: $<$ http://www.informaworld.com/smpp/content $\sim \mathrm{db}=$ all $\sim$ conte $\mathrm{nt}=\mathrm{a} 915460361 \sim \mathrm{frm}=$ titlelink ? words $=$ chemical, nutritional, $\mathrm{ch}$ anges,foods, during,extrusion $>$. Acesso em: 05 abr. 2011. doi: $10.1080 / 10408399009527513$.

CAVALHEIRO, F.Z. et al. Estudo do comportamento do consumidor de arroz. In: CONGRESSO DE INICIAÇÃO CIENTÍFICA, 16.; ENCONTRO DE PÓS-GRADUAÇÃO, 9., 2007, Pelotas, RS. Anais... Pelotas: UFPel, 2007. p.2.

CHEYNE, A. et al. Extrusion of cohesive potato starch pastes: I Rheological characterization. Journal of Food Engineering, v.66, n.1, p.1-12, 2005.

CHUANG, G.C.C.; YEH, A.I. Effect of screw profile on residence time distribution and starch gelatinization of rice flour during single screw extrusion cooking. Journal of Food Engineering, v.63, n.1, p.21-31, 2004.

CONAB (COMPANHIA NACIONAL DE ABASTECIMENTO). Acompanhamento da safra brasileira: grãos, sétimo levantamento, abril 2011. Brasília: Conab, 2011. 54p.

EL-SAIED, H.M. et al. Gelatinization, pasting characteristics and cooking behaviour of Egyptian rice varieties in relation to amylose and protein contents. Starch, v.31, n.8, p.270-274, 1979. Disponível em: <http://onlinelibrary.wiley.com/doi/10.1002/ star.19790310808/abstract>. Acesso em: 12 dez. 2010. doi: 10.1002/star. 19790310808 .

FAO (FOOD AND AGRICULTURE ORGANIZATION OF THE UNITED NATIONS). Statistical database, 2007. Disponível em:
$<$ http://faostat.fao.org/site/339/default.aspx $>$. Acesso em: 09 jan. 2011.

HAGENIMANA, A. et al. Evaluation of rice flour modified by extrusion cooking. Journal of Cereal Science, v.43, n.1, p.38-46, 2006. Disponível em: <http://www.sciencedirect. com/science?_ob=ArticleListURL\&_method=1ist\&_ ArticleListID $=1706512637 \&$ \&sort $=r \&$ st $=13 \&$ view $=c \&$ acct $=\mathrm{C} 000050221$ \&_version $=1 \&$ _urlVersion $=0$ \&_userid $=10 \& \mathrm{md}$ $5=1 \mathrm{~d} 0 \mathrm{~b} 3857 \mathrm{~d} 7 \mathrm{e} 05941 \mathrm{ea} 0 \mathrm{~d} 95 \mathrm{f} 69 \mathrm{c} 4 \mathrm{f} 9 \mathrm{~b} 89 \&$ searchtype $=\mathrm{a}>$. Acesso em: 09 jan. 2011. doi:10.1016/j.jcs.2005.09.003.

KADAN, R.S. et al. Functional properties of extruded rice flour. Journal of Food Science, v.68, n.5, p.16691672, 2003. Disponível em: <http://onlinelibrary.wiley.com/ doi/10.1111/j.1365-2621.2003.tb12311.x/abstract>. Acesso em: 12 dez. 2010. doi: 10.1111/j.1365-2621.2003.tb12311.x.

MARTINÉZ, C.; CUEVAS, F. Evaluación de la calidad culinária y molinera del arroz: guia de estúdio para ser usada como complemento de la unidad auditutorial sobre el mismo tema. 3.ed. Cali: Centro Internacional de Agricultura Tropical, 1989. $73 \mathrm{p}$.

MYERS, A.M. et al. Recent progress toward understanding biosynthesis of the amylopectin crystal. Plant Physiology, v.122, p.989-997, 2000. Disponível em: <http://www.plantphysiol. org/content $/ 122 / 4 / 989$. full? sid=32db4f3a-fbba-425a-ab9ce9c130f4e814>. Acesso em: 20 jan. 2011. doi: 10.1104/ pp.122.4.989.

SANTOS, A.B. dos et al. Manejo de água no comportamento da cultura principal e da soca de arroz irrigado. Pesquisa Agropecuária Brasileira, v.37, n.10, p.1413-1420, 2002.

SAS (STATISTICAL ANALISYS SYSTEM Realease 8.1). Cary, 2003. 10 CD-ROOM.

SEBIO, L. Efeito de alguns parâmetros operacionais de extrusão nas propriedades físico-químicas da farinha de inhame (Dioscorea rotundata). 1996. 106f. Dissertação (Mestrado em Tecnologia de Alimentos) - Faculdade de Engenharia de Alimentos, Universidade Estadual de Campinas, SP.

SOARES JÚNIOR, M.S. et al. Expansion and hydratation properties of cassava starch extruded with emulsifier. Brazilian Journal of Food Technology, v.2, p.57-61, 1999.

SHENG, D.Y. Rice-based ingredients in cereal and snacks. Cereal Foods World, v.40, n.8, p.538-540, 1995.

WALTER, M. et al. Arroz: composição e características nutricionais. Ciência Rural, v.38, n.4, p.1184-1192, 2008. 